\title{
Coworking, uma forma de organização de trabalho: conceitos e práticas na cidade de São Paulo
}

\section{Coworking, a form of organization of work: concepts and practices in the city of São Paulo}

\author{
Juliana Maria Moreira Soares ${ }^{1}$, Patricia Saltorato ${ }^{1}$ \\ ${ }^{1}$ Universidade Federal de São Carlos - UFSCar, São Carlos, São Paulo., Brasil
}

Autor para correspondência/Mail to: Patricia Saltorato patriciasaltorato@gmail.com

Financiamento/Funding: Capes

Recebido/Submitted: 31 Jul. 2015; Aceito/Approved: 15 Out. 2015

Copyright (C) 2015 Soares \& Saltorato. Todo o conteúdo da Revista (incluindo-se instruções, política editorial e modelos) está sob uma licença Creative Commons Atribuição-NãoComercial-Compartilhalgual 3.0 Não Adaptada. Ao serem publicados por esta Revista, os artigos são de livre uso em ambientes educacionais, de pesquisa e não comerciais, com atribuição de autoria obrigatória. Mais informações em http://ojs.c3sl.ufpr.br/ojs2/index.php/atoz/about/submissions\#copyrightNotice.

\begin{abstract}
Resumo
Introdução: este estudo teve como objetivo analisar o formato de organização de trabalho denominada coworking. Trata-se de um formato segundo o qual diversas empresas, coletivos ou profissionais liberais compartilham de um mesmo espaço, buscando a partilha dos custos relativos ao local de instalação. Neste, objetivou-se explorar como este sistema vem sendo praticado e considerado como uma alternativa à organização atual de trabalho em uma metrópole brasileira.

Método: utilizou-se o estudo de caso, tendo sido escolhidos para compor a análise e a exploração das práticas associadas a este conceito, três ambientes que operam segundo este sistema na cidade de São Paulo, Brasil. Foram realizadas quatro entrevistas com coworkers, e aplicados questionários junto a 24 indivíduos que trabalham em múltiplos ambientes de coworking.

Resultados: analisaram-se respostas e depoimentos relativos à motivação para inserir-se em um ambiente de coworking (divisão dos gastos, localização, flexibilidade, outros), as impressões sobre as trocas de experiências, o compartilhamento de interesses comuns; e as questões críticas de gestão de tais ambientes (espaço, segurança, outros).

Conclusão: foi possível inferir que esse sistema se apresenta como uma alternativa interessante para a organização do trabalho em uma cidade do porte de São Paulo, com especial destaque para a inovação e o empreendedorismo, ainda que a gestão dos espaços e dos relacionamentos requeiram maiores considerações.
\end{abstract}

Palavras-chave: Coworking; Organização do trabalho; Coletivos independentes; Espaços compartilhados

\begin{abstract}
Introduction: This study aims to analyze in the work organization format called coworking. This work organization format refers to several companies, groups or professionals that share the same space, seeking the sharing of expenses of the installation site. The objective was to visualize how this system has been practiced regarded as a form of current organization of work in a Brazilian metropolis.

Method: The methodology applied in this research based itself in a case study. It has been chosen to compose the practical and analysis of this concept, three environments within the city of São Paulo (SP - Brazil) who work amid this system. There, four coworkers have been interviewed and 24 individuals, working on multiple coworking environments had answered a questionnaire.

Results: Answers related to the motivation to engage in a coworking environment (costs sharing, location, flexibility, etc) have been analyzed alongside with the impressions related to the sharing of experiences and common goals and critical issues as related to the management of these spaces (common spaces, security etc).

Conclusion: The gathered data has allowed the conclusion that this organizational format presents itself as an interesting workspace organization in a city like São Paulo, especially when highlighting the innovation and entrepreneurship issues, although issues as space management and personal relationships still call for greater attention.
\end{abstract}

Keywords: Coworking; Organization of work; Independent collectives; Shared spaces

\section{INTRODUÇÃO}

Conviver no mundo significa essencialmente ter um mundo de coisas interpostas entre os que nele habitam em comum, como uma mesa se interpõe entre os que se assentam ao seu redor; pois, como todo intermediário, o mundo ao mesmo tempo separa e estabelece uma relação entre os homens (Arendt, 2007, p. 62).

Dentro do contexto atual de panoramas de organização do trabalho há uma busca constante por métodos colaborativos entre pessoas e empresas, principalmente entre indivíduos e iniciativas de pequeno porte. A procura por mecanismos de coesão entre os profissionais ante a incerteza envolvida nos processos de trabalho descrita por (Bauman, 2001, p. 170) como uma força individualizadora que torna os meios nebulosos, causando a perda dos interesses comuns - é uma alternativa que vem sendo cada vez mais explorada através de diversas formas e plataformas e em múltiplos níveis.

Esses novos contextos podem ser observados, por exemplo, nas formações de coletivos independentes e em construções de bases online de financiamentos mutuais e troca de serviços, bem como na adoção de grupos 
de trabalho (GTs) interdisciplinares em empresas de vários setores. Coletivos podem ser conceituados como grupos de trabalhadores com um foco em comum, normalmente formados via iniciativa independente e da área de artes e/ou humanas (Veloso, 2008). Sua atuação rotineiramente é feita “'por meio de empreitadas', escolhe-se um foco de interesse, um local para ocupar, ou tema agregador de grupos e artistas 'avulsos' e num tempo pré-estabelecido desenvolve-se o trabalho" (Veloso, 2008, p. 3). Por iniciativas de esforço colaborativo se elucidam com sucesso os exemplos de plataformas como o Catarse ${ }^{1}$, que permite a qualquer cidadão apresentar um projeto para receber investimento financeiro de pessoas físicas ou jurídicas; e da plataforma Corais ${ }^{2}$, que funciona como um sistema de design livre, visando à colaboração de profissionais para a realização diversos projetos mostrados no site.

Segundo Moriset (2014), o sistema de trabalho denominado de coworking emerge então a partir desse ambiente de iniciativas de colaboração voltado, porém, a profissionais de diferentes instituições - e não necessariamente de uma mesma área - tendo como foco o compartilhamento espacial do trabalho. Trata-se de um formato no qual diversas empresas, coletivos ou profissionais liberais dividem um mesmo espaço, buscando primordialmente a partilha dos gastos com o local de instalação. Visando a essa divisão de um espaço comum, o coworking abre diversas possibilidades de proximidade a esses trabalhadores, que provavelmente se encontrariam em posição de distanciamento uns em relação aos outros numa organização de trabalho convencional (e.g. funcionários de uma mesma empresa reunidos em salas, dividindo baias de trabalho, em um espaço somente voltado àquele negócio).

Tais possibilidades e peculiaridades deste arranjo laboral serão discorridas na presente pesquisa com base na análise de três exemplos captados em uma metrópole (São Paulo-SP, Brasil), visto ser uma cidade na qual o coworking tem se desenvolvido de forma pujante, segundo pesquisa do periódico Deskma (Orlandi, 2013). Assim, o presente estudo buscou identificar como o coworking vem sendo praticado no munícipio de São Paulo, por meio de estudo de casos, viabilizado via entrevistas e visitas em espaços esquematizados sob tal formato, além da aplicação de questionários a 24 indivíduos inseridos em ambientes de trabalho sob esse sistema.

\section{O CONCEITO DE COWORKING}

Moriset (2014) encontra as reminiscências de ambientes de trabalho conhecidos como coworking ainda no século XX, nos chamados caffés littéraires (cafés literários), como o Cabaret Voltaire, localizado em Zurich, Suíça, o qual foi é conhecido como local de nascimento do Dadaísmo, entre outros espaços correlatos estabelecidos em Paris, França. Este tipo de estabelecimento funciona como um ponto de encontro e de estudos, aliado às possibilidades dos serviços de um café, tendo sido palco de reuniões que levaram a idealização de muitos movimentos e vanguardas artísticas em diferentes momentos históricos.

Porém, o termo coworking emerge no ano de 1999, sendo cunhado por Bernie DeKoven - um game designer e teórico americano - ao desenvolver um novo tipo de plataforma coordenada por computadores. Tal sistema tinha como função colaborar com o trabalho em reuniões de negócios, informando aos presentes as notas mais importantes sobre a reunião em telas que fossem visíveis a todos, de maneira simultânea, baseando-se na ideia de "working together as equals" ${ }^{3}$. Ainda considerado como um dos primórdios da ideia de coworking, o espaço C-base - fundado em 1995 em Berlim, Alemanha - permanece aberto até hoje. Esse ambiente foi criado para ser utilizado por pessoas com interesse em tecnologia, ciência e temas ligados à ficção científica, com o intuito de compartilhamento de conhecimentos e colaboração com estudos sobre o assunto, e é considerado como o primeiro hackerspace da história. Entendem-se como hackerspaces os espaços físicos direcionados a comunidades de entusiastas de temas variados, visando estudar e trocar informações sobre determinado assunto. Os tipos mais comuns de hackerspace atualmente são os ambientes ligados a temas como computadores e tecnologia, arte industrial, robótica e eletrônica (Schlesinger, 2010).

A ideia atual de coworking consolidou-se em agosto de 2005, quando Brad Neuberg, um engenheiro de software americano, fundou um ambiente destinado a compartilhar espaços de trabalho em um centro comunitário voltado à mulher, chamado Spiral Muse e localizado em São Francisco, Estados Unidos (Botsman \& Rogers, 2011; Spinuzzi, 2012). Tratava-se de um espaço com capacidade para cinco a oito mesas destinadas a um trabalho a ser executado duas vezes por semana. $\mathrm{O}$ ambiente possuía características peculiares, tais como atividades relacionadas à meditação, alimentação, programação de passeios de bicicleta. Caracterizava-se igualmente pelo horário rígido de fechamento, fixado em $17 \mathrm{~h} 45$. Em entrevista à revista DeskMag ${ }^{4}$, Neuberg relata que a ideia não foi bem recebida de imediato (gerando pouca atenção de profissionais para a ocupação do lugar), quase levando o espaço a encerrar suas atividades após um ano. Porém, após alguma reestruturação, o projeto foi transferido para outro local, chamado Hat Factory, onde prosperou e consolidou sob essa forma de trabalho.

\footnotetext{
${ }^{1}$ Plataforma Catarse, recuperado de http://catarse.me/pt em 15 de out. 2014.

${ }^{2}$ Plataforma Corais, recuperado de http://corais.org/ em 15 out. 2014.

${ }^{3}$ Tradução nossa: "Trabalhando juntos igualmente”. MAGID, L. J. Outlining brings meeting to order. Los Angeles Times, 29 mar. 2000. Recuperado de http://articles.latimes.com/2000/mar/29/business/fi-13745 em 15 out. 2015.

${ }^{4}$ DULLROY, J. Coworking began at Regus... but not the way they think. Deskmag, 4 abr. $2004 . \quad$ Recuperado de http://www.deskmag.com/en/coworking-did-begin-at-regus-but-not-the-way-they-think-362 em 15 out. 2015.
} 
Lumley (2014) conceitua os espaços de coworking como "comunidades de trabalho onde empreendedores, autônomos e profissionais com flexibilidade quanto ao espaço de trabalho - aqueles trabalhadores criativos independentes - são capazes de se unir e trabalhar lado a lado, de forma independente ou em colaboração, assim como desejado" (Lumley, 2014, p. 40, tradução nossa ${ }^{5}$ ).

Depois de investigar estes espaços em Austin, Estados Unidos, Spinuzzi (2010) identifica ideia do coworking como sendo um sistema de ambientes formalmente pouco estruturados como escritórios e também bastante flexíveis quanto à agenda e horários. O autor acrescenta que são ambientes abertos a diversas possibilidades, tais como: a troca de recursos, informações e serviços; a tutoria; a formação de amizades, negócios e networking, entre outras eventualidades. Spinuzzi (2010) ainda pontua que, com a tendência da terceirização dos serviços pelas grandes empresas e com a crescente valorização do desenvolvimento dos profissionais, é muito provável que se propaguem variações dessas espécies de adocracias. A adocracia é uma expressão utilizada em Teoria das Organizações, popularizada pelo escritor Alvin Toffler. O termo é usado para designar formatos de trabalho variáveis, temporários e adaptativos, a serem realizados por equipes com profissionais com habilidades múltiplas e formações diversas, normalmente focados na realização de atividades complexas. É um paradigma que valoriza a flexibilidade e o holístico dentro do trabalho, rompendo com formas burocráticas (Correia, 2006).

Posteriormente, por meio de uma análise sobre o conceito e a prática do coworking, a qual parte da Terceira Geração da Teoria da Atividade (3GAT), de Yrjö Engeström, Spinuzzi (2012) traz novas ideias sobre este sistema, expondo que ele pode se consistir em uma rede de atividades a qual engloba "bons parceiros" e "boas vizinhanças" - significando indivíduos com boa convivência unidos em um determinado espaço, para o exercício de suas atividades. Dada à larga porosidade e mobilidade das estruturas urbanas, o autor ressalta a grande capacidade de modificação e variação destes espaços, estando implícita nessa ideia a elasticidade dentro da construção do conceito de coworking.

Segundo o website Coworking Wiki ${ }^{6}$, uma comunidade desenvolvida sobre uma plataforma colaborativa a qual dissemina ideias sobre o coworking, existe o compromisso com cinco valores fundamentais para caracterizar-se como tal, a saber: abertura, sociedade, acessibilidade, sustentabilidade e colaboração. A abertura consiste, segundo Chris Messina - gestor de ambientes de coworking e colaborador do website - em tomadas de decisões transparentes e inclusivas, dentro desse contexto de trabalho, visando a trocas de valor entre os membros. Messina ainda faz uma analogia com o corpo humano para explicitar esse ponto: "The human body is an 'open system' and thrives because of its openness. The human body is constantly exchanging things it values little for things it values more" (Hillman, 2011).

Na definição do Coworking Wiki, a importância da sociedade no contexto do coworking é colocada objetivamente: em primeiro lugar, as pessoas. Toda decisão tomada deve ser articulada entre todas as partes envolvidas, e o grupo vem em primeiro lugar nesse contexto, antes do individual. O coworking em si não trata de uma comunidade; o coworking é um espaço. Porém, é um espaço constituído de pessoas, tornando-se uma comunidade e, portanto, demandando toda essa rede de comunicação e confiança entre seus membros para que haja uma conexão entre os profissionais e compromisso com o funcionamento desse ambiente.

A ideia do ambiente acessível a quem quiser estar nele - como no caso de espaços com a presença de freelancers, trabalhadores diários, muitas pequenas empresas e correlatos, em constante trânsito - constrói no coworking essa faceta de "seleção própria" de seus participantes. Estabelecido um ambiente no qual as pessoas necessariamente têm o diálogo como um dos pontos cruciais para o bom desempenho, o coworking implica na ideia de autogestão grupal dentro de um espaço de trabalho, Este se baseia na acessibilidade e nos processos de decisão de maior contato entre as pessoas, promovendo o crescimento pessoal de cada indivíduo inserido nessa roda devido às constantes trocas, as quais não se restringem somente ao âmbito profissional. Ainda, essa abertura de espaço está ligada à flexibilidade, ao se criarem atmosferas não tão isoladas como em um escritório convencional - e tampouco tão distraídas como um café ${ }^{8}$ - balanceando-se de uma forma mais saudável no sistema do coworking (Lumley, 2014).

A sustentabilidade está ligada ao aspecto ambiental desse compartilhamento de espaço, uma vez que promove a divisão equitativa de recursos entre mais pessoas. Porém, a faceta sustentável não está somente ligada à esfera material, conectando-se também à questão da retroalimentação de serviços dentro do coworking. Isso significa que essa microssociedade no ambiente de trabalho pode ser capaz de se nutrir com seus próprios recursos (e.g. solicitando-se demandas práticas ao profissional que trabalha na mesa ao lado, suprindo suas necessidades de forma ágil). Segundo Thackara (2005), ser economicamente sustentável no contexto de trabalho significa

\footnotetext{
${ }^{5}$ Trecho original: "Coworking spaces are defined as work communities where independent entrepreneurs, freelancers, and professionals with workplace flexibility-those self-employed members of the creative class-are able to come together and work side by side, either independently or collaboratively as desired" (Lumley, 2014, p. 40).

${ }^{6}$ Recuperado de http://wiki.coworking.com/ em 15 de out. de 2014.

${ }^{7}$ Tradução nossa: "O corpo humano é um "sistema aberto", e prospera por causa de sua abertura. O corpo humano está constantemente trocando coisas que ele valoriza pouco para as coisas que valoriza mais".

${ }^{8}$ Exemplos desses diversos tipos de atmosfera podem ser encontrados no estudo de Spinuzzi (2012), no qual consta uma extensa análise sobre este sistema de organização baseado em um estudo multicasos, onde o autor visitou nove espaços de coworking nos Estados Unidos, entre os anos de 2008 e 2011.
} 
compartilhar recursos com eficácia, podendo incluir entre eles o tempo, habilidades, software, ou até mesmo alimentação.

O termo "colaboração" acompanha a ideia de aprender e ensinar. Ser um colaborador implica imersão no ambiente do coworking, aonde as trocas virão de maneira fluida, fazendo parte de um processo orgânico, demandando confiança e contato, em meio a tempos embrutecidos (Coworking Wiki, 2014).

Mediante o exposto, enxerga-se o design colaborativo como uma prática clara de desenvolvimento de projetos agregada ao modelo de coworking por diversos momentos, mostrando que essa forma de organização de trabalho pode ir além da questão do compartilhamento de espaço entre os profissionais. Outro pilar do coworking evidencia e propõe o protagonismo das relações interindividuais como uma proposta valiosa dentro do modelo. Não é incomum haver equipes de diferentes empresas trabalhando e colaborando em um mesmo projeto nesse sistema de trabalho, partilhando experiências e informações (Spinuzzi, 2012). Segundo Klein, Sayama, Faratin, e Bar-Yam (2001) o design colaborativo pode ser visto da seguinte forma: "O design colaborativo é realizado por vários participantes (sendo eles indivíduos, equipes ou até mesmo organizações como um todo) e cada um é potencialmente capaz de propor valores para questões de design e/ou avaliar essas escolhas, a partir de sua perspectiva particular" (Klein et al., 2001, p. 2, tradução nossa ${ }^{9}$ ).

Ainda nessa linha, a conceituação de trabalho em equipe também se constitui como outro termo coligado à ideia do coworking. Entendida como um "Conjunto ou grupo de pessoas que, ao desenvolver uma tarefa ou trabalho, almejam um objetivo único, obtido pelo consenso/ negociação: esse conceito amplia o anterior na medida em que o objetivo do trabalho não é definido externamente ao grupo ou por parte dos seus componentes. O objetivo é resultante da discussão/negociação entre todos os membros da equipe" (Piancastelli, Faria, \& Silveira, 2000, p. 46), assemelha-se à definição de design colaborativo e pode, de maneira similar, ser aplicável ao coworking, à exemplo da questão da decisão da partilhas espaciais.

No entanto, Spinuzzi (2012) postula que nem todos os coworkers enfatizam a abertura às colaborações, confirmando o aspecto de heterogeneidade nos espaços de coworking. Ainda, o autor considera a existência de três modelos de coworking: o community working space, que se configura como um espaço de trabalho em comunidade, com espaços de conversação delimitados (como áreas externas e lounges); o unoffice model, cujos principais objetivos consistem no diálogo, compartilhamento de ideias e trocas profissionais, de maneira bastante flexível; e o tipo definido como federated work space, o qual também se descreve como um ambiente desenhado pelos proprietários/fundadores pensando no fomento das relações de trabalho, como colaboração entre equipes e networking, porém de maneira formal ou informal.

Pode-se entender, portanto, que uma vez que as diferentes empresas e/ou profissionais liberais se unem sob um mesmo teto para a realização de seus respectivos ofícios, ao menos um objetivo maior em comum é fixado e sempre será existente no coworking: o compartilhamento do ambiente e gastos referentes às instalações físicas e de toda ordem concernente ao funcionamento desse espaço. Tal objetivo é negociado e discutido entre os diferentes atores presentes no acordo em um primeiro momento, ou estudado e estipulado pelo proprietário do espaço, resultando na geração de valor que seja atraente às partes potencialmente envolvidas e interessadas na ocupação deste tipo de espaço de trabalho - como proprietários de pequenos negócios, profissionais freelancers e consultores (Spinuzzi, 2012). Assim, outros laços encadeados a partir dessa união, emergida entre os coworkers, podem ser construídos e oxigenados a partir da dinâmica espacial propiciada pelo ambiente.

Ressalta-se que apesar do crescimento de espaços de coworking pelo mundo, essa temática ainda permanece com poucos estudos ao seu redor (Hurry, 2012). Um pequeno número de pesquisas e reportagens protagoniza o panorama relativo ao conceito, panorama histórico e evolução do coworking, caracterizadas fortemente por publicações estrangeiras, conforme exemplos explorados neste trabalho.

\section{O COLETIVO-INDIVIDUAL}

É possível visualizar a potencialidade do coworking para muito além da partilha de espaço, movendo-se ao encontro de uma nova noção de relacionamento interpessoal no ambiente de trabalho - ou nem tão nova assim, pois para Clastres (1974), a prosperidade de certos antigos povos indígenas sul-americanos estava ligada à manutenção de pequenas populações, onde o sistema de uma sociedade primitiva funcionava, conforme correlaciona o antropólogo Thiago Carvalhaes. Dentro dessas sociedades, havia melhores formas de relacionamento entre as pessoas, e isso se refletia na dimensão social mais saudável aos indivíduos (formada por esses grupos menores, em aldeias) (Clastres, 1974): o crescente aumento desses agrupamentos poderia levar à formação futura de estruturas como a de um Estado, ausentes até então (e por isso tais sociedades são pejorativamente denominadas de arcaicas), com todo o seu conteúdo composto de hierarquizações e focadas em objetivos ligados ao poder. Analogamente a tal análise, a relação entre grupos menores, como da organização de trabalho no caso do coworking - onde normalmente organizam-se entre si empresas com um pequeno número de profissionais,

\footnotetext{
9 "Collaborative design is performed by multiple participants (representing individuals, teams or even entire organizations), each potentially capable of proposing values for design issues and/or evaluating these choices from their own particular perspective" (no original).
} 
ou mesmo profissionais liberais - poderia satisfazer os processos de trocas e de entendimento, na medida em que esses pequenos grupos são mais capazes de preservar a identidade dos indivíduos, mas, ao mesmo tempo, com a manutenção mais fluida dos canais de contato entre eles.

Nesse canal de troca em um coletivo cabe ainda uma aproximação com a noção de agenciamento de Deleuze e Parnet (1998), Neste se cria um processo simbiótico presente no espaço comum às pessoas dentro de um contexto - territorializando esse sítio de trabalho via constantes intercâmbios, nos quais

[a] relação, entendida como agenciamento, é o modo de funcionamento de um plano coletivo, que surge como plano de criação, de co-engendramento dos seres. Cabe ressaltar que este plano coletivo e relacional é também o plano de produção de subjetividades (Escóssia \& Kastrup, 2005, p. 9).

A valorização dessas trocas em um ambiente que permite que o profissional tenha a sua liberdade de trabalho igualada à autonomia de interação com outros profissionais de outras áreas e empresas, traz organicidade ao espaço. O funcionamento do coworking, então, ao trazer tal elemento orgânico essencial ao desempenho do ambiente e do indivíduo, acaba por criar um coletivo-individual. Parte significativa do movimento para a gestão deste holos (todo) do coworking depende do emaranhado coletivo de profissionais em ação de forma horizontal, e não somente de uma "cabeça” ou um setor para a resolução de casos que venham a surgir (e.g. setor de relações humanas). Porém, se o indivíduo tem independência dentro de seu trabalho, igualmente tem a oportunidade de poder compartilhar experiências e ideias com esse mesmo trabalhador-gestor de espaço que está ao lado, no momento em que mais for conveniente, e onde for mais propenso a isso - tendo em vista que espaços de coworking geram ambientes de convivência abertos para trocas. Enfatizando essa importância, conforme aponta Thackara (2005), recentes estudos evidenciam o grande aspecto de valorização por parte dos indivíduos a valores subjetivos e não-materiais, como autonomia e relações sociais, da mesma forma que valorizam bens tangíveis e serviços.

Em suma, em uma sociedade onde cada vez mais as relações entre as pessoas são intermediadas por redes sociais, conexões sem fio e mensagens instantâneas, essa volta - ou resistência - do contato humano real dentro de um coletivo, apresenta-se como o componente aparentemente de maior força e atração do coworking. Bauman (2011) sumariza essa ideia de perda de aspectos essenciais e sinérgicos entre os indivíduos, que convive dentro deste processo, pois para o autor:

O contato face a face é substituído pelo contato tela a tela dos monitores; as superfícies é que entram em contato. Por gentileza do Twitter, "surfar”, o meio de locomoção preferido em nossa vida agitada, cheia de oportunidades que nascem e logo se extinguem, afinal chegou à comunicação inter-humana. O que se perde é a intimidade, a profundidade e durabilidade da relação dos laços humanos (Bauman, 2011, p. 18).

Nessa esfera de pensamento sobre as relações contemporâneas, nas quais a fragilização e multifacetação dos laços são traços cada vez mais corriqueiros, ainda cabe uma breve abordagem acerca da questão da metrópole. Fresca (2011) considera o aspecto polissêmico do conceito de metrópole, e impassível de uma conceituação unívoca, devido à sua fluidez espacial e temporal. No entanto, analisa que há uma linha de autores que enfatiza os ângulos funcionais no conceito, na qual consta a divisão do trabalho como um dos aspectos importantes à consideração estrutural da metrópole, estando este sempre em reconstrução e reconciliação apoiados nos processos capitalistas dominantes (Fresca, 2011).

Processos contínuos de rearranjo implicam na formação de novas morfologias urbanas, criando assim, novas problemáticas e distâncias tangíveis e intangíveis, onde se encontra lugar para a emergência de espaços que provocam uma nova configuração laboral, a exemplo da estruturação coworking. Moriset (2014) relaciona o papel do coworking no cenário de produção contemporâneo com o conceito de “Terceiro Lugar” de Oldenburg (1984), ligando à ideia da criação de um espaço rico em possibilidades e conexões, flexível e coerente ao momento de transformação das urbes em "Cidades Criativas ${ }^{10 ", ~ c i t a n d o ~ m e t r o ́ p o l e s ~ n e s s a ~ c o n t e x t u a l i z a c ̧ a ̃ o, ~ c o m o ~ P a r i s, ~}$ Berlim e Nova Iorque.

\section{METODOLOGIA}

A abordagem metodológica adotada pauta-se no estudo de casos (Yin, 2005), no qual a utilização de certas técnicas foi fundamental para a elucidação do tema. A condução de entrevistas e aplicação de questionários se constituiu nas principais estratégias de aproximação e imersão com o tema, além da realização da observação não participante em um espaço de coworking, constituindo-se em métodos essenciais à condução desta pesquisa exploratória. Entre os três tipos de pesquisas propostos por Yin (2005), divididas em descritiva, exploratória e explicativa, entende-se que coube ao presente estudo de caso uma abordagem exploratória, e com caráter

\footnotetext{
${ }^{10}$ Não há uma conceituação exata para delinear as chamadas Cidades Criativas (Creatives Cities), porém é possível apontar algumas características que remetem a este tipo de cidade, a exemplo da grande capacidade de mudanças e criação de conexões entre seus diversos setores, além da existência de uma elevada massa trabalhadora pertencente ao setor criativo de produção e da forte presença de desenvolvimento nas esferas de alta tecnologia e biotecnologia (Pratt, 2008; Reis \& Kageyama, 2009).
} 
qualitativo, no qual se buscou considerar a diversidade de temas relativos ao assunto principal encontrada no decorrer do estudo.

As entrevistas de cunho exploratório são abordagens essenciais para adentrar-se no campo investigativo desejado, além de reconhecer novas questões e ampliar os horizontes sobre o objeto de pesquisa (Quivy \& Campehoudt, 1998). Quatro indivíduos integrantes de três espaços de coworking (coworking A, coworking B e coworking C) situados em São Paulo (SP - Brasil) foram entrevistados, com base em roteiros de entrevistas semiestruturadas. Tais atividades com os coworkers ocorreram pessoalmente e também por trocas de e-mails. Foram feitos registros fotográficos pelos autores, e também houve a cessão do uso das imagens registradas por parte dos entrevistados. Outras interações, pequenas entrevistas e verbalizações espontâneas com demais indivíduos ligados à temática também compuseram esse cenário.

Gil (1987/1999) expõe que o questionário é uma importante técnica de pesquisa social, a qual é formada por um determinado número de questões, a qual objetiva colher os interesses, opiniões, expectativas, vivências e afins dos indivíduos sobre determinados assuntos. Esta técnica foi utilizada, e um questionário contendo dezesseis questões, entre perguntas abertas e fechadas, foi enviado a membros de espaços de coworking da cidade de São Paulo (SP - Brasil). Foram obtidos 24 retornos por completo, os quais foram utilizados na geração de dados analisados por esta pesquisa.

Sintetizando, o ciclo metodológico do presente estudo foi composto por quatro etapas, as quais se descrevem através de um primeiro momento de revisão bibliográfica, seguido pela coleta de dados, posteriormente partindo para a análise e discussão dos resultados e à construção das considerações finais.

\section{RESULTADOS E DISCUSSÃO: CASOS DE COWORKING EM UMA METRÓPOLE}

Conforme explicitado na seção de Metodologia, quatro indivíduos que integram de três espaços distintos de coworking da cidade de São Paulo (SP - Brasil) fazem parte desta abordagem inicial do estudo. Um destes espaços, aqui identificado como coworking A (Figuras 1.a .b), iniciado em 2013, identificaram-se dois dos entrevistados. O terceiro entrevistado trabalha no coworking B (Figura 1.c), que foi fundado em 2012, e o último entrevistado integra um espaço - iniciado no ano de 2011- mas que não leva nome oficial, sendo definido aqui como coworking C (Figura 1.d). Nesta seção também figuram os resultados de um segundo momento do estudo, no qual os questionários foram preenchidos por coworkers de sete espaços diferentes da capital paulistana, utilizados para colaborar com a construção do panorama, que é exposto a posteriori.

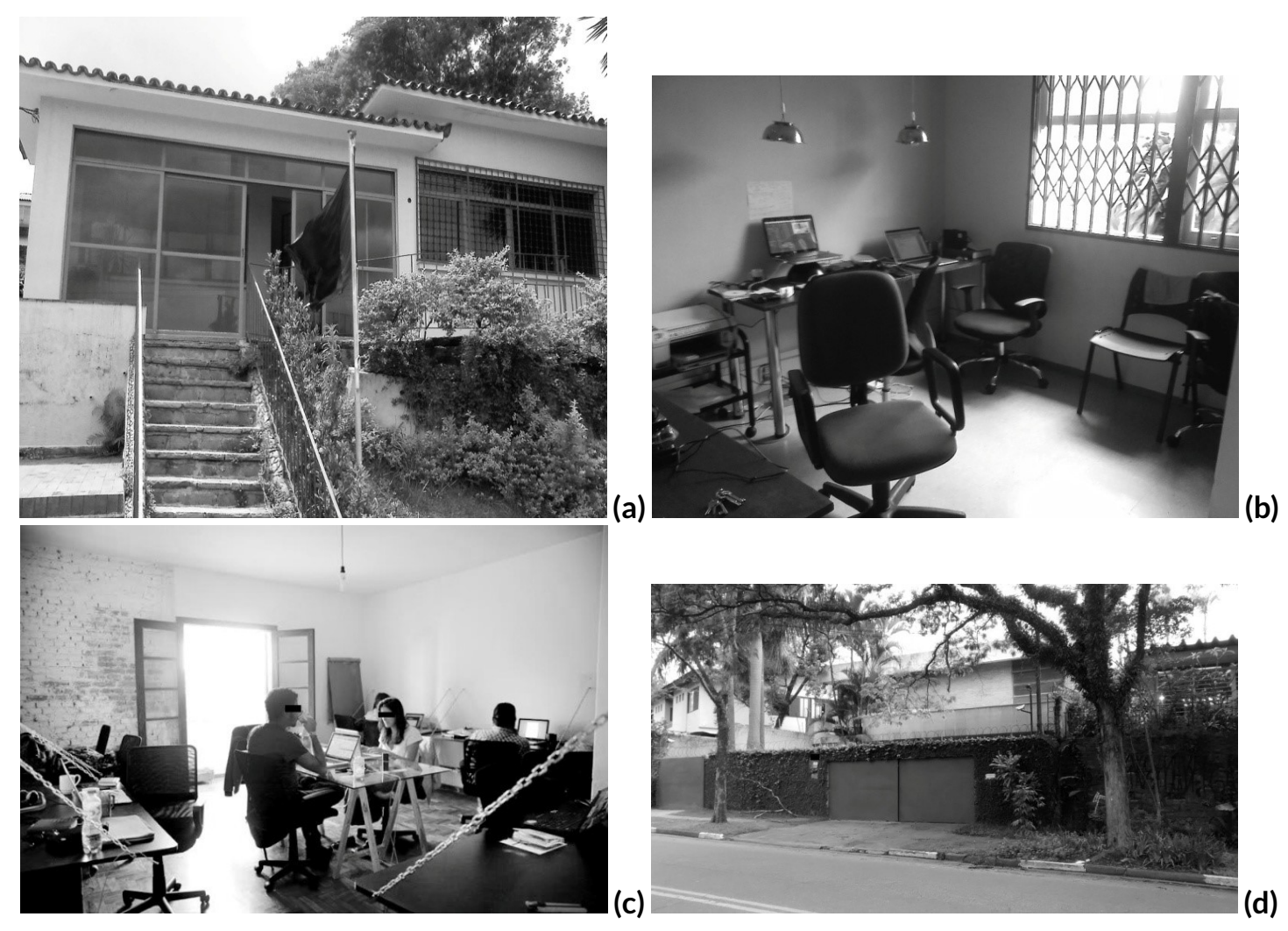

Figura 1. (a) Escadaria de entrada do espaço A. (b) Uma das salas do espaço A. (c) Uma das salas em uso do espaço B. (d) Fachada arborizada do coworking C.

Fonte: (a, b) Coworker do espaço A. (c) Coworker do espaço B. (d) as autoras.

Três dos entrevistados estão ligados à criação dos espaços que trabalham. Com relação ao surgimento dessa 
ideia do coworking, as razões apresentadas são bastante próximas. Além da divisão dos gastos com a locação do imóvel, as intensivas trocas de experiências, compartilhamento de interesses comuns e a questão da maior autonomia permitida nesse tipo de organização, são os motivos mais citados pelos entrevistados, bem como é reportado pela bibliografia da área (Lumley, 2014; Moriset, 2014; Spinuzzi, 2010, 2012).

Um dos coworkers do ambiente A chegou a relatar que a economia financeira não foi significativa, comparada ao espaço anterior que locavam (o qual também funcionava como um coworking em São Paulo). Porém, o contato e a afinidade entre as empresas e profissionais liberais que se juntaram no novo lugar foi um fator decisivo, no qual se desenvolveu um número significativo de parcerias e trocas (profissionais e sociais) entre os novos integrantes. No entanto, a questão dos gastos tende a ser um motivo norteador para essa escolha, tendo em vista que os valores de locação de espaços comerciais em uma metrópole como a paulistana beiram inviabilizar a projeção de um negócio próprio, segundo depoimento do coworker do espaço C. O gráfico da Figura 2 totaliza os dados obtidos pela aplicação dos questionários, explicitando os motivos ligados à escolha, em um primeiro momento, pelo coworking.

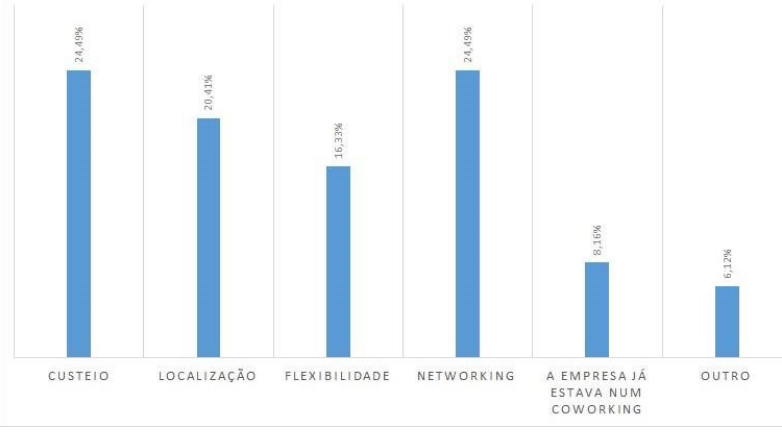

Figura 2. Os motivos que levaram os respondentes a se inserir num sistema de coworking. Fonte: as autoras.

A questão do custo figura-se como o principal motivo para a opção por este sistema em um primeiro momento, seguido por razões de criação de conexões profissionais, ou networking. Importante destacar que a faixa etária dos profissionais que integram essas casas varia entre 25 e 32 anos que, no contexto dos respondentes da pesquisa, situou-se ao redor de 31 anos. Excetua-se um caso no espaço B, pois dois extremos peculiares foram encontrados e que não correspondem à média dos espaços analisados: neste espaço, o trabalhador mais jovem tem 17 anos, e atua em atividades de entrega de materiais e documentos, enquanto o mais velho tem 38 anos. $\mathrm{O}$ depoimento do entrevistado do coworking $C$ agrega uma explicação a este item, pois, a partir de sua experiência neste tipo de sistema, ele percebe que cada vez mais profissionais recém-saídos de seus primeiros espaços de formação (e.g. universidades) se decepcionam com os mecanismos rígidos impostos por grandes empresas e escritórios da área, e tendem a se mover para organizações menores ou iniciar seu negócio sob plataformas flexíveis, a exemplo do que o modelo de coworking oferece. Ressalta-se que a média de tempo sob a qual os indivíduos desta pesquisa trabalham sob tal modelo situa-se ao redor de 13 meses.

Os locais analisados na pesquisa (coworkings A, B e C) têm entre sete e treze empresas instaladas, sendo organizações constituídas por uma pessoa apenas ou integradas por um número pequeno funcionários (de dois a quatro profissionais), todos eles instalados em casas que contam com cerca de treze profissionais em cada espaço. As áreas de atuação dessas empresas, coletivos e profissionais liberais são múltiplas, com predominância no setor de artes e humanas (e.g. empresas focadas em design, produção audiovisual e manutenção de diversos projetos web). Essa configuração alinha-se aos aspectos da análise de Moriset (2014) quanto à percepção do coworking como sendo um espaço de oxigenação e regeneração dos ambientes urbanos (na criação das chamadas “Cidade Criativas”). Nestes, é possível manter a configuração profissional de parte significativa dos trabalhadores alocados em distintos setores, o que provoca um florescimento da indústria criativa em modelos mais sustentáveis de existência, mesmo com os múltiplos percalços e restrições propostos pelos modos predominantes de produção atuais.

A preferência por um recinto amplo foi percebida durante a pesquisa com os entrevistados, somando-se a isso a predileção por casas com áreas externas, em detrimento de apartamentos ou outros modelos arquitetônicos mais fechados; aspectos que demonstram a vocação integradora do coworking. Esse tipo de planta permite a criação de áreas de convivência, ou seja, tem caráter mais flexível e aberto a realização de atividades sincrônicas. No caso do espaço A (Figuras 3.a .b), instalado em uma casa ampla, com múltiplas salas, cozinha, garagem e quintal, desenvolvem-se atividades de jardinagem, confraternizações, ensaios com instrumentos musicais e sessões de ioga. Há suportes para bicicletas e é permitida a entrada (e permanência) de animais de estimação.

Um dos entrevistados pondera que esses espaços também são essenciais, dada à dinâmica de uma cidade tão grande como São Paulo, onde quaisquer deslocamentos para a realização de atividades extras facilmente se transformam em um caos particular-coletivo, quando se depende do transporte público ou veículo particular em 

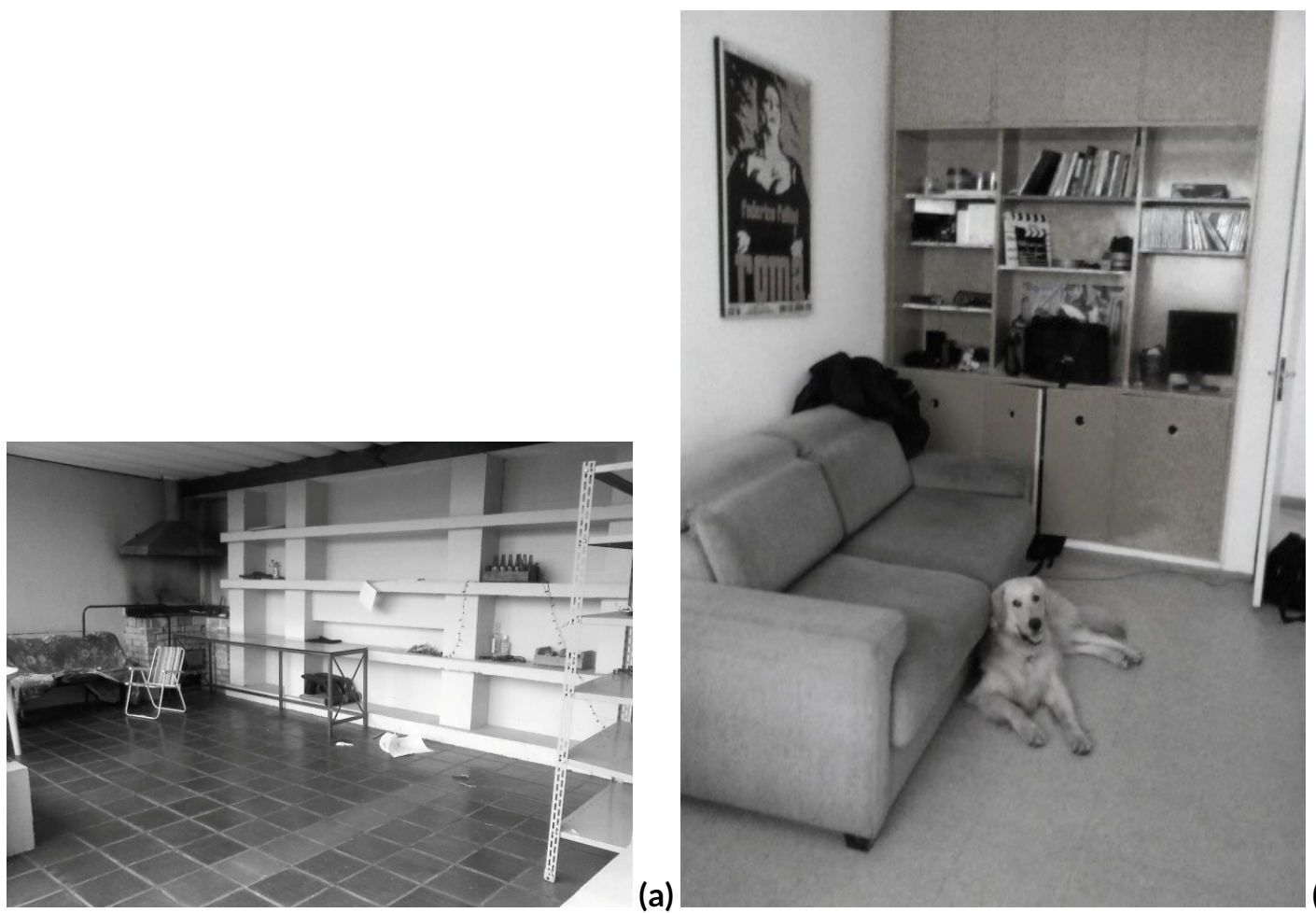

(b)

Figura 3. (a) Parte do espaço externo do espaço A. (b) Um cão foi ao trabalho com seu dono no espaço A. Fonte: (a) as autoras. (b) Coworker do espaço A.

horários de pico, por exemplo. Observou-se que aproximadamente $71 \%$ dos coworkers que responderam ao questionário tem espaços destinados à convivência e realização de atividades extras em seus locais de trabalho, e, de maneira geral, relatam essa abertura como uma experiência positiva: "Já teve meditação, relaxamento, respiração, dança, etc. São atividades que influenciam positivamente minha produtividade e provocam autoconhecimento", relatou um dos respondentes.

Esse descolamento temporário do ambiente de trabalho, constituindo-se em uma espécie de fuga momentânea dedicada ao lúdico e ao lazer, é uma razão interessante e estimulante dentro dessa lógica e chama a atenção para a necessidade de flexibilização dentro dos moldes-padrão de organização de trabalho convencionais. Dumazedier (1973) destaca que o lazer não deslegitima as obrigações do trabalho, e tampouco o rejeita através dessa ociosidade, mas sim provoca um reequilíbrio útil entre as demandas do ser humano, tendo a capacidade ainda de desenvolver a personalidade e a criatividade. O engessamento dos meios e métodos do modelo empresarial regular, com padrões restritos de cumprimentos de horários e espaços delimitados, mediado por burocracias e meritocracias, impõe um paradigma distanciado dos mecanismos naturalmente reconhecidos como propulsores de rendimento e inovação, relacionados aos livres diálogos, atividades lúdicas e de relaxamento. Um entrevistado do espaço A ressalta a importância da existência desses ambientes onde as subjetividades sejam valorizadas (Figura 4) e cita uma ideia inspiradora relativa a tal prática ao falar sobre espaços dedicados ao descanso, como a siesta (pequeno cochilo pós-almoço): “(...) há sociedades indígenas em que as decisões coletivas, que direcionam os trabalhos religiosos do grupo, escolhas de ocupação de território, etc, são tomadas com base nos sonhos".

O modo de dividir as contas varia entre essas casas: pode ser baseada no número de membros da empresa, organizações não governamentais, coletivos e afins presentes (reajustando-se de acordo com a entrada e saída de pessoas no decorrer do tempo), ser fixado, ou ainda oscilar de acordo com a quantidade de cômodos ou o tamanho dos espaços ocupados. Há abertura para trabalhadores freelances (espécie de temporários) em dois desses espaços (coworkings A e B), sendo cobrado um valor proporcional a eles, como por exemplo, com base nos valores pagos pelos demais grupos que dividem as casas (pondera-se o valor individual em relação ao número de integrantes das iniciativas grupais). Um aspecto em comum foi notado entre todas as dinâmicas de divisão de gastos dos espaços A, B e C: a situação financeira desses grupos ou profissionais individuais é levada em consideração ao se calcular os valores a serem cobrados. Os depoimentos relatam e reforçam muito o ponto da confiança no momento em que os profissionais se agregam aos espaços, dialogando com os indivíduos já presentes no ambiente sobre as suas possibilidades financeiras do momento. A coworker do espaço B explica que o fato de o grupo pagar a quantia que for possível no momento acompanha a ideia de que, depois de certo tempo, com o crescimento profissional, esse valor aumente em igual proporção - ou seja, seu desenvolvimento empresarial não deixa de ser subsidiado em alguma medida pela oportunidade daquele espaço de coworking.

Ainda, no caso do espaço B, há uma unidade sistematizada voltada à administração do espaço e responsável 


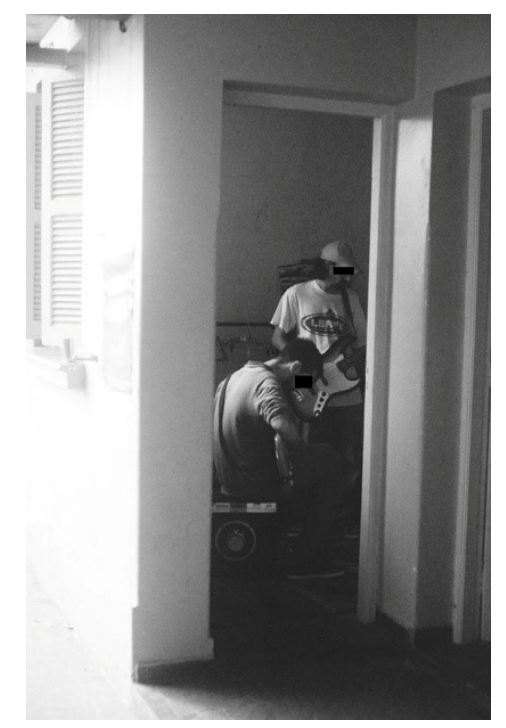

Figura 4. Integrantes do espaço ensaiando em sala externa com instrumentos musicais dentro do ambiente. Fonte: as autoras.

pela captação e produção de projetos, com o intuito de agregar o maior número de integrantes possível ao ambiente. A remuneração dos profissionais que trabalham nesta unidade não está incluída nas cotas mensais pagas pelos integrantes do estabelecimento ou nos ganhos provenientes de oficinas realizadas na própria casa, as quais são dedicadas diretamente ao pagamento das contas e gastos relativos ao espaço. Essa unidade de articulação, portanto, é custeada pela própria captação e realização dos projetos. Dessa forma, o espaço B propõe minimizar a possibilidade de conflitos nesta esfera, uma vez que a questão da gestão do espaço foi apontada pelos respondentes como sendo o tópico mais complexo na vivência dentro de um coworking, com $37,5 \%$ das respostas apontando para este aspecto como sendo um ponto crítico.

Autores pontuam que o local partilhado por diversos profissionais, de áreas distintas e com bagagens múltiplas, abre caminho para o desdobramento de duas fortes tendências em negócios, que são também dois dos pontos fortes do coworking: a inovação e o empreendedorismo. O dinamismo e a flexibilidade do modelo do coworking mostram-se, de certa forma, próximos a conceitos que as corporações vêm implantando ou tentando implantar, de maneira especializada e "ultra focada" (como em GTs, por exemplo), visando a estimular novas ideias, com vista à atualização e manutenção de suas fatias de mercado. Este aspecto é evidenciado na fala dos entrevistados e respondentes, e pontuado como sendo um diferencial enfático e positivo deste tipo de sistema. A atomização de múltiplos saberes e possibilidades em um mesmo local se contempla como um ponto forte em uma cidade como São Paulo, com ampla extensão territorial e múltiplos problemas comuns de deslocamento entre espaços, causando essa dificuldade de encontros dos indivíduos face-a-face. Dois depoimentos podem ser destacados neste particular:

"É um ambiente em que conheço muita gente, de diversas áreas, que podem me ajudar no meu negócio. O ambiente é muito estimulante pela energia dos empreendedores e pelas oportunidades de negócio" (Respondente F, 36 anos).

"Em geral, as pessoas que optam por trabalhar em coworkings tendem a ter uma cabeça mais aberta com relação a formato, metodologia e processos de trabalho, especialmente quando se trata de colaboratividade. Esta característica é fundamental para mim hoje" (Respondente M, 30 anos).

Ambientes de coworking distinguem-se das iniciativas regulares de trabalho justamente por aplicarem de forma natural e sinérgica os conceitos que, sob as esferas administrativas recorrentes, parecem ser praticados ainda de forma pouco dinâmica e desentendida quando confrontados com o restante da máquina empresarial (e.g. equipes de trabalho dentro de empresas que chegam a ideias inovadoras "fora do padrão", mas são barrados pela alta cúpula de negócios). Conforme os relatos obtidos, essa organização em estilo horizontal e em menor escala - pressupondo um todo orgânico, pautada na troca de experiências, referências, amizades e networking - mostram-se potencialmente eficaz nesse viés do germinar da inovação, bem como do empreendedorismo, uma vez que, a partir de um investimento pequeno mensal (quando em comparação ao aluguel de outro tipo de espaço, em uma cidade que sofre com o boom da especulação imobiliária, como a capital paulistana), é possível estruturar-se de maneira a montar um novo negócio, em um ambiente suscetível a aprendizados e colaborações diversas ou, como manifestou um dos respondentes, o "Coworking [como] possibilidade de pequenas empresas e startups terem uma estrutura física. Networking e custo facilitados”. Após a vivência nesse sistema $66,66 \%$ dos respondentes apontaram a questão do networking como o maior ponto positivo do coworking, e $45,83 \%$ desses indivíduos ponderaram a questão da partilha de gastos, seguidos pela opção ligada às facilidades de relacionamentos interpessoais, e também da localização dos espaços. 
Nessa forma de trabalho versátil está também a flexibilidade das horas laborais. Em todos os casos estudados, os profissionais não possuem um horário determinado para entrar e sair do "escritório". É consenso entre os grupos desses ambientes que o ritmo é único e distinto a cada ser humano, ante rígida equalização de horários, presente na maior parte das organizações. Uma das variáveis mais importantes com relação à escolha das rotinas de trabalho está ligada ao sono, o que respeita os três cronótipos identificados na população humana, ou seja, os matutinos (aqueles que dormem e despertam naturalmente cedo), vespertinos (os que dormem e despertam naturalmente tarde) e indiferentes (os quais não têm preferências); além de outros fatores cronobiológicos, como o número de horas necessárias ao sono (Horne \& Ostberg, 1976 apud Mello, Esteves, Comparoni, BeneditoSilva, \& Tufik, 2002). Assim, entende-se que uma parcela das pessoas tem preferência por iniciar suas atividades do dia mais cedo, enquanto outra não. Esse processo de autonomia e decisão quanto ao início do trabalho proporciona maior estímulo e rendimento ao profissional, conforme pode ser observado no relato da coworker do espaço B: “(...) o X (coworker) chega umas 10h e pouco, e a $Z$ (coworker) e eu chegamos mais perto do almoço, para fechar a casa, porque não gostamos de acordar cedo e funcionamos muito melhor à noite. Assim, o trabalho fica bem mais saudável, tanto mental quanto fisicamente".

Quanto ao design colaborativo, para muitos projetos, é imprescindível que haja cooperação entre os diversos profissionais do espaço, como o caso do espaço B. Vários projetos captados pela unidade de articulação do espaço só ocorrem por meio dessa participação mútua: garante-se uma habilidade de um coletivo de um lado, e de uma empresa por outro e, assim, via o diálogo entre essa unidade e os grupos chega-se a uma equipe multidisciplinar, a qual trabalha sob o mesmo teto, com um objetivo em comum, mas em organizações distintas. O depoimento abaixo ilustra esta condição:

“O fato de não trabalhar sempre com as mesmas pessoas, conhecer indivíduos novos, novas áreas etc, é relevante, pois abrimos mais espaço para o conhecimento. Além de ter a questão de respeitar o outro, com direitos iguais, indiferente de hierarquia, talvez um comportamento organizacional, mas não tão formal. Não existem grandes mudanças no escritório comum, as pessoas ficam no mesmo lugar, com a mesma equipe, e se a equipe for ruim, é um ponto crítico, pois as pessoas não conseguem ser espontâneas, construir relações colaborativas" (Respondente N, 26 anos).

De acordo com o resultado das entrevistas, é comum as empresas indicarem-se entre si para a realização de trabalhos, quando há demanda específica e se verifica que uma pode "cobrir" a atividade da outra. Pequenos favores também são trocados entre elas, conforme depoimento de um coworker do espaço A (que trabalha com audiovisual) ao relatar que os empréstimos de materiais e a realização de pequenos serviços (como a idealização de um logotipo para a empresa ao lado) são constantes. A parceria entre os colaboradores ainda leva a realizações além do espaço do coworking, a exemplo de um projeto de intervenção urbana que foi idealizado por três profissionais de diferentes empresas do espaço A, o qual é existente até os dias atuais. Ainda, a amizade é uma palavra bastante citada entre os participantes da pesquisa, ficando claro que essa esfera da colaboração e dos diálogos constantes traz uma maior e positiva abertura ao relacionamento interpessoal: "De brinde, ainda ganhamos bons amigos", diz um dos coworkers do espaço A. Nos questionários, 95,83\% das respostas obtidas indicam positivamente que ambientes de coworking tendem a privilegiar e fortalecer as diversas formas de trocas, as quais não se prendem somente ao cunho profissional, mas extensíveis também à esfera social de convívio.

As desvantagens do modelo também foram observadas. Toda a questão de compartilhamentos múltiplos, além da divisão financeira dos gastos com o espaço físico, permeia a partilha de valores próximos entre os profissionais envolvidos nesse ambiente, quanto à convivência em um coletivo. Muitas resoluções dependem do despertar da iniciativa de um membro e tão logo, da colaboração de outros a reboque, para que a modificação se concretize. Essa demanda por proatividade em um ambiente de gestão horizontal é um problema em potencial, conforme expuseram alguns entrevistados. A gestão do espaço é o tópico apontado como o mais crítico dentro do modelo, conforme foi anteriormente exposto (Figura 5).

Entre os outros aspectos críticos do coworking para os indivíduos participantes desta pesquisa, são citadas questões relativas a níveis de ruído no ambiente, diminuição de graus de privacidade, e espaço reduzido para armazenamento material. Duas dessas situações foram reportadas por Hurry (2012) em um estudo realizado sobre um coworking da cidade de Halifax, Canadá, ligadas ao fator sonoro e de privacidade, sendo indicados como fatores de alto incômodo aos coworkers. $\mathrm{O}$ autor explicita certos conhecimentos tácitos dos trabalhadores para a resolução desse tipo de problema, como por exemplo, a adoção do uso de fones de ouvido.

No caso do espaço $\mathrm{B}$, certa dificuldade foi relatada com relação à implementação da unidade de articulação citada anteriormente, devido ao fato de nenhum dos responsáveis por este núcleo da casa ter formação ou experiência em administração (basicamente profissionais da área de humanas integram esta equipe). Neste caso, a administração inicial do local e da parte comercial dos projetos, bem como o primeiro capital para a reforma e adequação do espaço, exigiu da equipe esforços sob a forma de "mutirões".

Em nenhuma casa há uma espécie de "manual de conduta” sobre a vivência nesses espaços, tampouco foi descrito algo correlato através dos questionários, mas identificou-se a aplicação de diversas técnicas, formais 


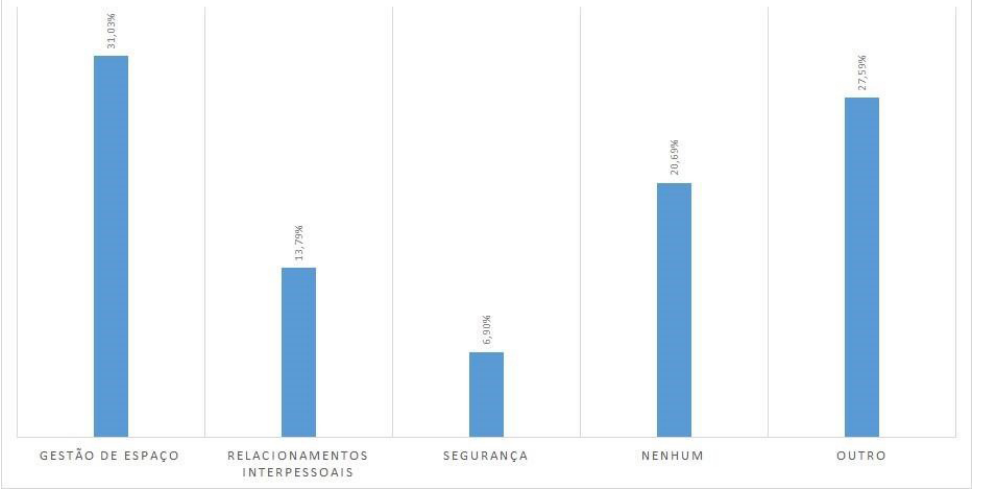

Figura 5. Pontos críticos entendidos como desvantagens do sistema de coworking pelo grupo de entrevistados. Fonte: as autoras.

e informais, com a intenção de manter-se um alinhamento das atividades dentro do ambiente. Grupos de e-mails direcionados a todos os membros, bem como conversas casuais nos corredores e nas atividades de convivência, costumam dar bom encaminhamento às situações com potencial de se tornarem problemas, segundo os depoimentos. Reuniões periódicas com todos os membros também são mecanismos adotados por uma das casas, como no espaço B. No espaço A houve recentemente uma decisão coletiva pela escolha de um dia da semana para a realização de mutirões, com foco no cuidado da casa: pinturas, pequenas reformas, decorações, reordenação do espaço e afins. Nenhum participante relatou experiências traumáticas ou problemas graves em seus ambientes que fossem além da questão dos desafios de convivência humana: “(...) isso não é necessariamente uma desvantagem. É trabalhoso, mas é, na verdade, um grande aprendizado", relata a coworker do espaço B.

\section{CONCLUSÕES}

O coworking se figura como uma forma de organização de trabalho a qual busca oferecer uma maior flexibilidade em termos de custos de locação ao indivíduo, majoritariamente procurado por trabalhadores em situação de free-lance, ou em pequenas empresas e startups. Observou-se que o coworking é buscado por indivíduos que dispõem de pouco capital de investimento para a locação de um espaço de trabalho, ou não tem interesse em investir grande parte de seu rendimento nesta parte do negócio. Conforme os relatos coletados, destaca-se que a cidade de São Paulo - cujo alto custos de vida, problemática com relação ao deslocamento - beneficia-se da existência desse tipo de sistema de trabalho, o qual busca articular de uma maneira mais equilibrada com estes tipos de constrições. No entanto, pode-se ressaltar que também foram indicados pontos negativos com relação ao sistema, os quais pairam majoritariamente sobre a questão de inter-relacionamentos e gestão do ambiente.

Mediante as possibilidades identificadas nos resultados deste estudo, foram traçados pontos nos quais o sistema do coworking, potencialmente, tem a colaborar:

a) Empreendedorismo versus falta de capital, aliada à grande especulação imobiliária nos grandes centros urbanos: apresenta-se como uma solução financeiramente negociável em grande parte dos casos, ou mesmo de menor custo, interessante ao profissional com pouco capital e recém-ingresso no mercado de trabalho;

b) Autonomia e espaço concedido ao profissional dentro do trabalho versus rendimento: conforme relatos, a flexibilidade encontrada dentro desses espaços não se traduz em menor produtividade, resultando em motivação para a realização de projetos (tanto dentro como fora do ambiente de trabalho) e crescimento profissional;

c) Sustentabilidade versus boom de pequenos negócios (demandando cada vez mais espaços de locação e, logo, exercendo mais pressão nos recursos ao seu redor): o compartilhamento de um espaço e sua consequente melhor utilização, ainda com a possibilidade de partilha de materiais internos, coloca em pauta a sustentabilidade inerente a esse modelo;

d) Era dos relacionamentos ligados por mecanismos frágeis (e.g. redes sociais, mensagens instantâneas e afins) versus relações pessoais reais para consolidação de certos tipos de projetos (colaboração) e networking: as ligações reais entre as pessoas são enfatizadas e concentradas em um espaço físico, tanto socialmente como profissionalmente, estimulando esse convívio essencial, atualmente distanciado pela dinâmica de vida das grandes cidades e pelos meios tecnológicos abundantemente à disposição.

Todo o funcionamento do coworking, nos espaços analisados, visa amenizar/resolver situações de conflito, ressaltando-se a necessidade de manutenção de um sistema real de comunicação explícita entre as pessoas. Este 
é um ponto crítico na sociedade contemporânea, pois a comunicação oral e presencial tem sido substituída por gadgets e redes sociais que imprimem um aparente tom de pessoalidade nas trocas entre os seus usuários - os quais na verdade estão distanciados por espaços mínimos, departamentalizações e angústias da vida moderna perdendo-se, então, os simbolismos e as subjetividades presentes na tônica das relações do tipo face a face; o que foi citado e valorizado pelos respondentes nesta forma de trabalho.

Dessa forma, dois obstáculos figuram com persistência na expansão do coworking: o desafio da manutenção dos relacionamentos tangíveis entre as pessoas e o entendimento da sociedade de que os modi operandi de organizações de trabalho mais flexíveis são produtivos, contrastando-o com o lugar comum/tradicional. O sistema de coworking pode possibilitar visões e relações de trabalho (e sociais) diferenciadas, mesmo que se identifiquem pontos negativos que irão requerer revisões sistêmicas pelos engajados na proposta, e compatíveis com o atual "tempo de modernidade líquida” de Bauman (2001). Espera-se que o presente estudo possa estimular a discussão acerca do funcionamento deste sistema de trabalho, contribuindo com o desenvolvimento de futuros estudos sobre a temática. 


\section{REFERÊNCIAS}

Arendt, H. (2007). A condição humana (10a. ed.). Rio de Janeiro: Forense Universitária.

Bauman, Z. (2001). Modernidade líquida. Rio de Janeiro: Zahar.

Bauman, Z. (2011). 44 cartas do mundo líquido moderno. Rio de Janeiro: Zahar.

Botsman, R., \& Rogers, R. (2011). What's mine is yours: The rise of collaborative consumption. New York: Collins.

Clastres, P. (1974). A sociedade contra o estado. Recuperado em 12 out. 2015, de https://we.riseup.net/assets/71282/ clastres-a-sociedade-contra-o-estado.pdf

Correia, A. C. G. (2006). Burocracia ou será burrocracia: o retardo do trabalho com eficiência e qualidade (Monografia de Pós-Graduação Lato Sensu em Administração de Qualidade). Universidade Cândido Mendes, Rio de Janeiro.

Coworking Wiki. (2014, Out.). Plataforma colaborativa sobre coworking. Recuperado em 30 abr. 2014, de http:// wiki.coworking.com/w/page/16583831/FrontPage

Deleuze, G., \& Parnet, C. (1998). Diálogos (E. A. Ribeiro, Trad.). São Paulo: Escuta.

Dumazedier, J. (1973). Lazer e cultura popular. São Paulo: Perspectiva.

Escóssia, L., \& Kastrup, V. (2005, maio/ago.). O conceito de coletivo como superação da dicotomia indivíduo-sociedade. Psicologia em Estudo, 10(2), 295-304. doi: 10.1590/S1413 $-73722005000200017$

Fresca, T. M. (2011, ago./dez.). Uma discussão sobre o conceito de metrópole. Revista da ANPEGE, 7(8), 31-52. doi: 10.5418/ra.v7i8.177

Gil, A. C. (1999). Métodos e técnicas de pesquisa social (5a. ed.). São Paulo: Atlas. (Trabalho original publicado em 1987)

Hillman, A. (2011, Ago.). Coworking core values 3 of 5: openness. Recuperado em 15 out. 2015, de http://dangerouslyawesome.com/2011/08/ coworking-core-values-3-of-5-openness/

Hurry, C. J. P. (2012). The hub halifaz: a qualitative study on coworking (Mestrado em Administração de Empresas, St. Mary's University, Halifax). Recuperado de http://library2 .smu.ca/handle/01/24826

Klein, M., Sayama, H., Faratin, P., \& Bar-Yam, Y. (2001). What complex systems research can teach us about collaborative design. In 6th international conference on computer supported cooperative work in design (p. 5-12). London, Ont.. doi: 10 .1109/CSCWD.2001.942221

Lumley, R. M. (2014). Coworking project in the campus library: supporting and modeling entrepreneurial activity in the academic library. New Review of Academic Librarianship, 20(1), 49-65. doi: 10.1080/13614533.2013.850101

Mello, M. T., Esteves, A. M., Comparoni, A., Benedito-Silva, A. A., \& Tufik, S. (2002, maio/jun.). Avaliação do padrão e das queixas relativas ao sono, cronotipo e adaptação ao fuso horário dos atletas brasileiros participantes da paraolimpíada em sidney - 2000. Revista Brasileira de Medicina do Esporte, 8(3), 122-128. doi: 10.1590/S1517-86922002000300010

Moriset, B. (2014). Building new places of the creative economy: The rise of coworking spaces. In 2nd geography of innovation international conference 2014 (p. 1-25). Utrecht. Recuperado de https://halshs.archives-ouvertes.fr/ halshs-00914075/document
Oldenburg, V. T. (1984). The making of colonial lucknow: 1856-1877. United Kingdom: Princeton University.

Orlandi, D. (2013, 23 de Maio). Coworking in brazil. Deskmag. Recuperado em 15 out. 2014, de http://www.deskmag.com/ en/coworking-spaces-in-brazil-sao-paulo-812

Piancastelli, C. H., Faria, H. P., \& Silveira, M. R. (2000). O trabalho em equipe. In J. P. Santana (Ed.), Organização do cuidado a partir de problemas: uma alternativa metodológica para a atuação da equipe de saúde da família. Brasília: OPAS.

Pratt, A. (2008). Creative cities: the cultural industries and the creative class. Geografiska Annaler: Series B - Human Geography, 90(2), 107-117. doi: 10.1111/j.1468-0467.2008 .00281.x

Quivy, R., \& Campehoudt, L. (1998). Manual de investigação em ciências sociais (2a. ed.). Lisboa: Gradiva.

Reis, A. C., \& Kageyama, P. (2009). Creative city perspectives. São Paulo: Garimpo de Soluções.

Schlesinger, J. (2010). Founding a hackerspace (Monografia de Bacharelado em Ciências). Faculty of Worcester Polytechnic Institute. Worcester Polytechnic Institute, Worcester.

Spinuzzi, C. (2010, Mar.). What coworking tell us about the future of work. In South by southwest interactive panel. Austin: University of Texas. Recuperado em 29 out. 2015, de http://pt.slideshare.net/spinuzzi/spinuzzi-sxswi2010

Spinuzzi, C. (2012, Out.). Working alone together: coworking as emergent collaborative activity. Journal of Business and Technical Communication, 26(4), 399-441. doi: $10.1177 / 1050651912444070$

Thackara, J. (2005). In the bubble: designing in a complex world. Cambridge: The MIT Press.

Veloso, V. G. (2008). Grupo ou coletivo: uma questão de tempo. In V Congresso da Associação Brasileira de Pesquisa e Pós-Graduação em Artes Cênicas (p. 1-4). Belo Horizonte.

Yin, R. K. (2005). Estudo de caso: planejamento e métodos (3a. ed.). Porto Alegre: Bookman.

\section{Como citar este artigo (APA):}

Soares, J. M. M. \& Saltorato, P. (2015). Coworking, uma forma de organização de trabalho: conceitos e práticas na cidade de São Paulo. AtoZ: novas práticas em informação e conhecimento, 4(2), 61 - 73. Recuperado de: http://dx.doi.org/10.5380/atoz.v4i2.42337 